\title{
THE ANALYSIS OF MATERIAL REMOVAL RATE OF WEDM MINIATURE GEARS
}

\author{
Ashish Goyal $^{1 *}-$ Vyom Singh $^{1}-$ Abhishek Patel $^{1}$
}

${ }^{1}$ Department of Mechanical Engineering, Manipal University Jaipur, Dehmi Kalan, Jaipur, Rajasthan, India, 303007

\begin{tabular}{|c|c|}
\hline ARTICLE INFO & Abstract: \\
\hline $\begin{array}{l}\text { Article history: } \\
\text { Received 19.09.2019. } \\
\text { Received in revised form 08.02.2020. } \\
\text { Accepted 19.02.2020. }\end{array}$ & $\begin{array}{l}\text { Gear fabrication in wire electrical discharge machining (WEDM) } \\
\text { plays an important role in manufacturing industries. This paper } \\
\text { describes the analysis and optimization of process parameters for } \\
\text { the fabrication of spur gear on brass spur gear on brass }\end{array}$ \\
\hline $\begin{array}{l}\text { Keywords: } \\
\text { WEDM } \\
\text { miniature spur gear } \\
\text { material removal rate } \\
\text { response surface methodology } \\
\text { scanning electron microscopy }\end{array}$ & $\begin{array}{l}\text { workpiece }(10 \mathrm{~cm} x 15 \mathrm{~cm} x 6 \mathrm{~mm}) \text { material by wire EDM process. } \\
\text { The experiments were performed by using the design of } \\
\text { experiment (DoE) approach and the material removal rate } \\
(M R R) \text { was analyzed by response surface methodology technique. } \\
\text { The effect of input parameters i.e. pulse on time, pulse off time } \\
\text { and feed rate on MRR has been investigated. The surface }\end{array}$ \\
\hline DOI: https://doi.org/10.30765/er.1520 & $\begin{array}{l}\text { geometry of the gears has been analysed by the Scanning } \\
\text { Electron Microscopy (SEM). This study found that } 0.4 \mu \text { s for } \\
\text { pulse on time, } 60 \mu \text { sor pulse-off time and } 6 \mathrm{~mm} / \mathrm{min} \text { for feed rate } \\
\text { provides improved material removal rate. The analysis of } \\
\text { variance shows that pulse on time and feed rate are the } \\
\text { significant parameters for the wire EDM process. The SEM } \\
\text { image exhibits the capability of WEDM to machined miniature } \\
\text { gear with a uniform distribution of regular-shaped craters and } \\
\text { defect-free flank surface. }\end{array}$ \\
\hline
\end{tabular}

\section{Introduction}

Miniature gears are widely used in the industrial and scientific field. Mostly such gears are used in robotics, scientific instruments, miniature pumps, mechanical watches. Micro gears have an outer diameter of less than $1 \mathrm{~mm}$ whereas the meso gears have an outer diameter ranging from $1 \mathrm{~mm}$ to $10 \mathrm{~mm}$, i.e., $1 \mathrm{~mm}<$ $D_{\text {o }}<10 \mathrm{~mm}$. Gear manufacturing process is mainly divided into two parts, i.e. forming and machining. These conventional methods come with some limitations while manufacturing of miniature spur gear, due to such limitations wire electric discharge machining (WEDM) is widely acknowledged for the manufacturing of miniaturized components. Gupta et al. has reviewed the machining at high and low energy discharge parameters and encountered frequent wire breakage and deterioration in surface finish also a cause for unstable machining with very slow cutting rate [1]. Bouquest et al. has performed an experiment and compared the fabrication process of a gear prototype. The comparison between different fabrication processes like WEDM, rapid prototyping, and milling process have been done for the fabrication of prototype gears [2]. Ali et al. found that conventional WEDM can be used to machine miniaturized gear components with least compared to micro WEDM, and it is recommended to use thin wire electrode diameter and low energy discharge to achieve high surface finish [3]. Gupta et al. concluded that wire EDM can be used to eliminate the wire lag, and it has a better surface finish than gear hobbing [4]. Jung et al. proposed a new method to reduce the load on the helical gears. Cr-Mo steel and aluminum alloys used a raw material and experiments have been performed. The finite element method (FEM) was used to analyses the results [5]. Mohapatra et al. optimized the WEDM input parameters by using Taguchi's loss function. Moreover, the single pitch deviation is significantly affected by interaction between pulse off time and wire feed rate [6]. Goyal has performed experiments on Inconel 625 super alloy by the cryogenic wire EDM

\footnotetext{
* Corresponding author

E-mail address: ashish.goyal@jaipur.manipal.edu
} 
process. The design of experiments methodology was used to analysis the effect of process parameters on the material removal rate and surface finish [7]. Benavides et al. performed experiments for the fabrication of the miniature ratchet wheel by micro WEDM process, and the surface characterization has been performed to analyse the surface characteristics of the specimen [8]. Goyal et al. investigated the effect of different tool electrodes on the machining surface of Inconel 625 alloy by the Taguchi's optimization techniques. They found that the pulse on time and peak current mostly affect the material removal rate and surface characteristics [9]. Later it is essential to examine the consequence of machining parameters on the machining characteristics during the fabrication of spur gear by the WEDM process. The present work is focused on the optimization of machining parameters by the response surface methodology (RSM) approach. Also, the surface characteristics have also presented the fabricated spur gears.

\section{Experimental details and RSM approach}

For the present research work, brass plate of $6 \mathrm{~mm}$ thickness was used as a workpiece material to perform the experiments. The experiments were performed on Wire EDM (Electronica Maxicut) machine using half hard brass wire of $0.25 \mathrm{~mm}$ diameter as a tool electrode and distilled mineral water as dielectric medium. Three input parameters, i.e. pulse on time, pulse off time and wire feed rate were selected and the ranges for these were set according to machine limitations and upon the basis of preliminary experiments. The variation of these parameters was used to investigate the material removal rate. A square workpiece of $10 \mathrm{~cm} \times 15 \mathrm{~cm} \times 6 \mathrm{~mm}$ was taken for machining. The material removal rate was measured in $\mathrm{mm}^{3} / \mathrm{min}$. The material removal rate is calculated by the following formula:

$$
\mathrm{MRR}=\frac{d \times l \times h}{t} \mathrm{~mm}^{3} / \mathrm{min}
$$

Where $t$ is the machining time, $h$ is the height of the workpiece and $l$ is the length of the cut and $d$ is the kerf width. The total 9 experiments have been performed according to orthogonal array. The DoE approach is a procedure that applies orthogonal arrays of statically designed experiments to obtain the best results with a minimum number of experiments, thus reducing experimentation time and cost. In the Taguchi method, the signal to noise ratio $(\mathrm{S} / \mathrm{N})$ is used for the determination of quality characteristics. Therefore, total 9 gears were fabricated. Figure 1 presents the wire EDM set up and Figure 2 shows the machined miniature spur gears specimen. The Table 1 presents the input parameters and their range for the experimental work.

Table. 1 input parameters and their range.

\begin{tabular}{cccccc}
\hline Symbol & Control factor & Unit & Level 1 & Level 2 & Level 3 \\
\hline A & Pulse on time & $\mu \mathrm{s}$ & 1 & 3 & 4 \\
B & Pulse off time & $\mu \mathrm{s}$ & 6 & 8 & 10 \\
C & Wire feed rate & $\mathrm{mm} / \mathrm{min}$ & 5 & 6 & 7 \\
\hline
\end{tabular}

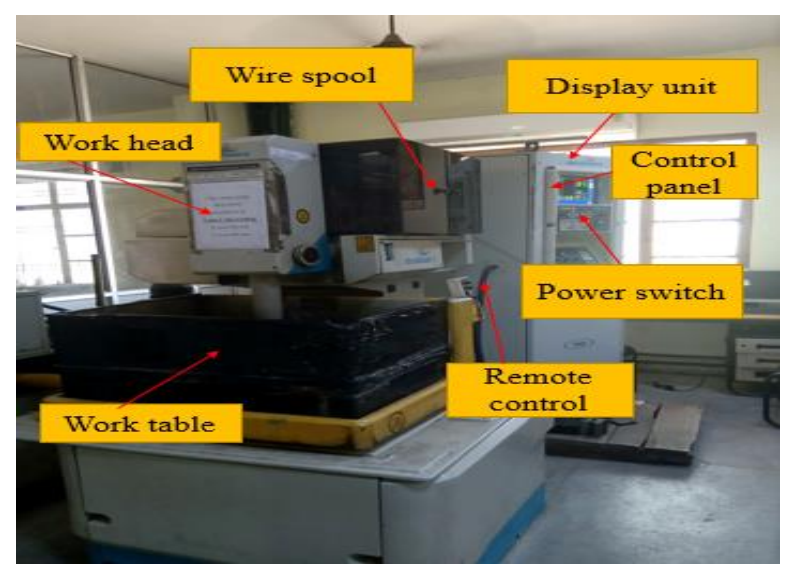

Figure 1. WEDM machine setup. 


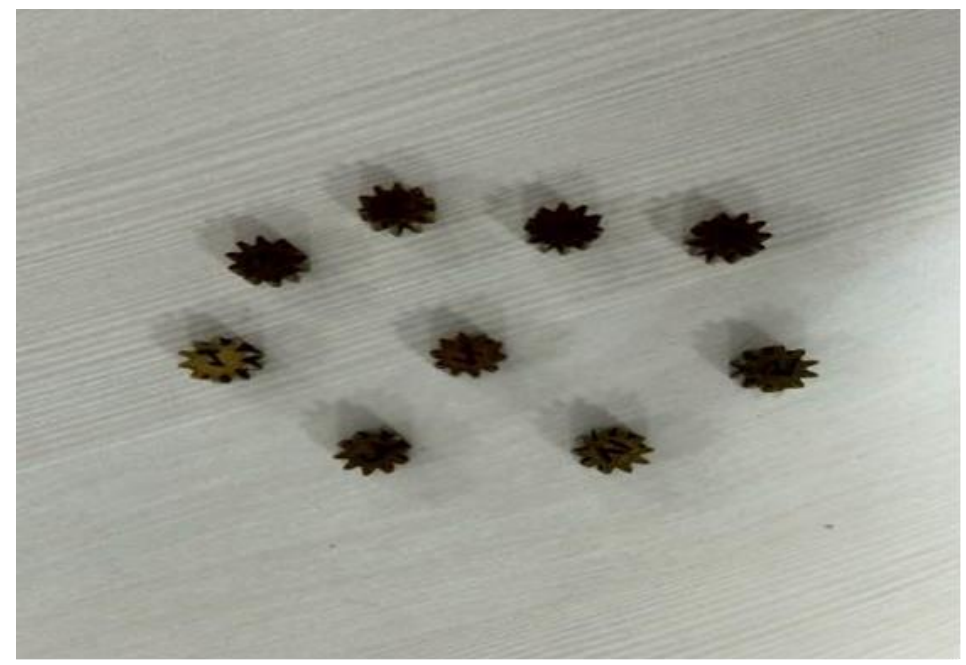

Figure 2. fabricated miniature gears (dia $>10 \mathrm{~mm})$.

The response surface methodology approach is the procedure used for determining the conditional behaviour of various process parameters and the output parameters in order to find the problem and to rectify the problem. The RSM is a collection of mathematical and statistical methods useful for modelling of engineering problems. The main utilization of the RSM is for the optimization of the responses which are of the key interest of influence for other responses.

$$
y=f^{\prime}(x) \beta+\text { è }
$$

Where $\mathrm{y}$ is the response of the interest and the input variable are denoted by $x_{1}, x_{2} \ldots . . x_{n} . f(x)$ is a vector function of $p$ elements that consists of power and cross-products of power of $x_{1}, x_{2} \ldots . . . x_{n}$ up to a certain degree, $\beta$ is a vector of $p$ constant coefficients referred to as parameters and $\dot{e}$ is a random experimental error. There are two important models used in the RSM. This is the first-degree model:

$$
y=\beta_{o}+\sum_{i=1}^{k} \beta_{i} x_{i}+\text { è }
$$

\section{The Box-Behnken design is an experimental design of response surface methodology}

The Box-Behnken designs are a class of rotatable or nearly rotatable second order designs based on 3level incomplete factorial designs. This cube consists of the central point and the middle point of the edge. Table 2 shows the value of orthogonal array and the response parameter. The design expert software has been used for the modeling of the parameters. The analysis of variance (ANOVA) approach has been used to analyze the significant process parameters.

Table 2. Orthogonal array and response parameters.

\begin{tabular}{ccccc}
\hline Run & Ton $(\mu \mathrm{s})$ & Toff $(\mu \mathrm{s})$ & WF $(\mathrm{mm} / \mathrm{min})$ & MRR $\left(\mathrm{mm}^{3} / \mathrm{min}\right)$ \\
\hline 1 & 0.1 & 80 & 7 & 6.06 \\
2 & 0.1 & 60 & 6 & 6.97 \\
3 & 0.1 & 100 & 5 & 6.46 \\
4 & 0.4 & 80 & 6 & 7.87 \\
5 & 0.4 & 60 & 5 & 8.47 \\
6 & 0.4 & 100 & 7 & 7.27 \\
7 & 0.3 & 80 & 5 & 8.69 \\
8 & 0.3 & 60 & 7 & 6.97 \\
9 & 0.3 & 100 & 6 & 7.57 \\
\hline
\end{tabular}




\section{Result \& Discussion}

\section{Effect on material removal rate:}

Figure 3 (a) and (b) shows the 3D surface plot and normal residual plot respectively for the material removal rate. It is observed that higher the pulse on time is it leads to faster erosion of the material from the surface and results in high spark energy discharge increasing the material removal rate. When the pulse on time is high, it produces strong electric-field which increases the transfer period of discharge energy to the electrode which results in rapid melting and evaporation of a large amount of material [10-11].
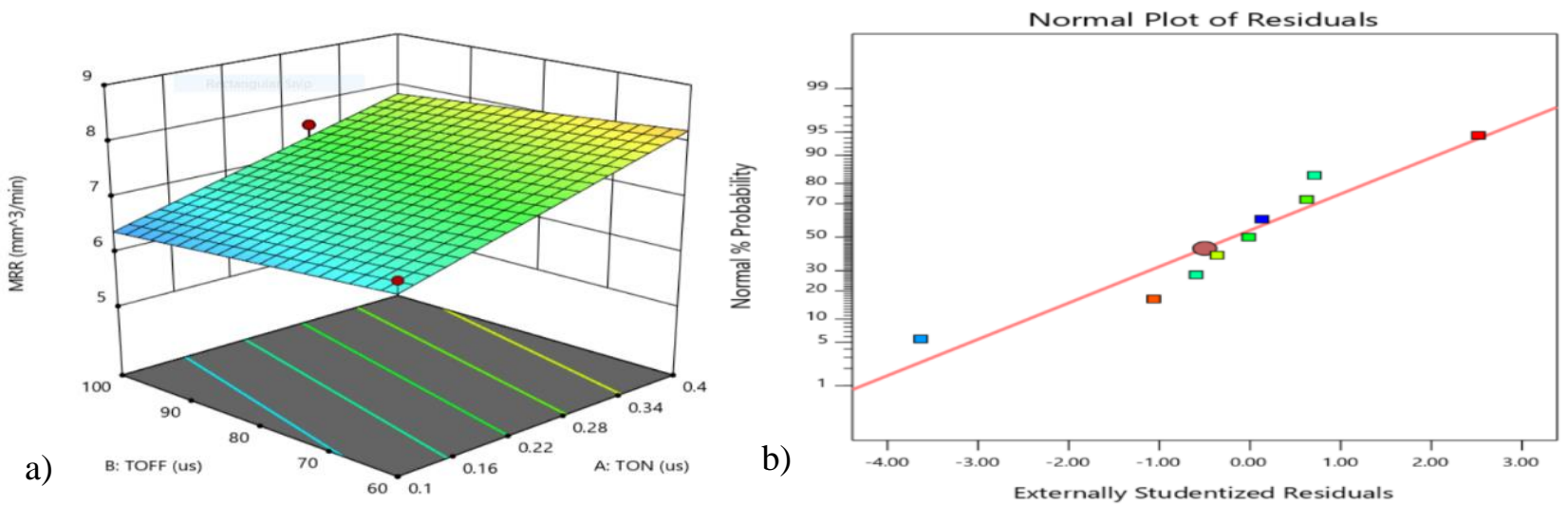

Figure 3. 3D surface plot for MRR (a), and normal residual plot (b).

During low feed rate, the material removal rate is the highest. When the feed rate is high, it reduces the duration of spark location at a particular location of the spark on the wire, leading to a decrease wire lag and low material removal rate. When there is low feed rate, it exposes the wire to handle more discharge energy per wire length, which may increase wire-breakage [7]. When the pulse-off time is increased, the material removal rate decreases as the discharge energy increases resulting in an increase of the spark efficiency forming irregular deeper caters. Figure 4 shows the good agreement between the residual and the experimental run. Table 3 presents the ANOVA analysis of the process parameters.

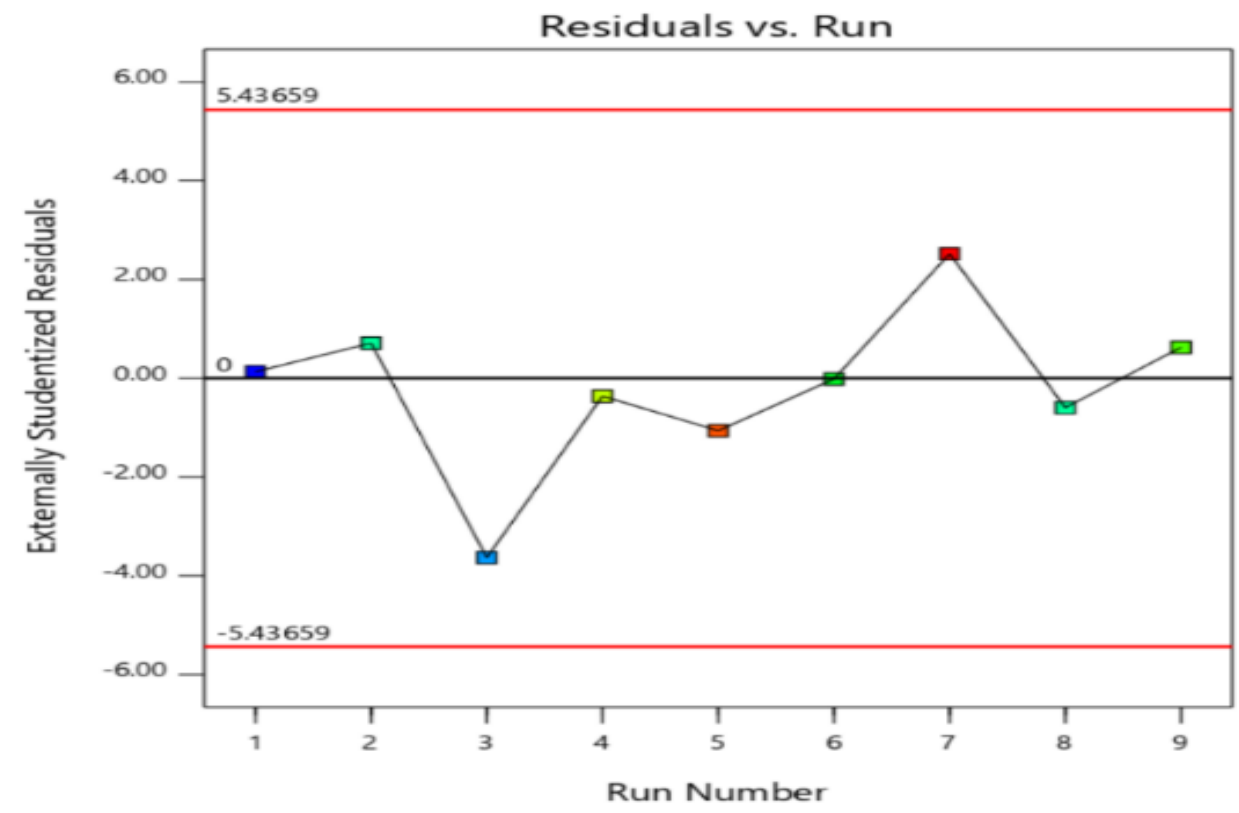

Figure 4. The graph between run number and residual. 
Table. 3 ANOVA results of MRR.

\begin{tabular}{cccccc}
\hline Source & Sum of squares & DF & Mean Square & F-value & p-value \\
\hline Model & 5.3 & 3 & 1.77 & 10.65 & 0.0131 \\
Ton & 3.26 & 1 & 3.26 & 19.66 & 0.0068 \\
Toff & 0.20 & 1 & 0.20 & 1.24 & 0.3161 \\
Wf & 1.83 & 1 & 1.83 & 11.04 & 0.0209 \\
Residual & 0.82 & 5 & 0.1659 & & \\
Total & 6.13 & 8 & & & \\
\hline
\end{tabular}

The ANOVA analysis shows the pulse on time and the feed rate as the significant parameters for the MRR. The obtained $R^{2}$ value is $86.46 \%$ showing that the model has good agreement with the results. The developed mathematical model is used to predict the material removal rate using design expert 11 software.

Regression equation of the MRR:

$$
Y_{\mathrm{MRR}}=7.29+0.7239 * A+0.1852 * B+0.5525 * C
$$

\section{Material Characterization of miniature spur gear}
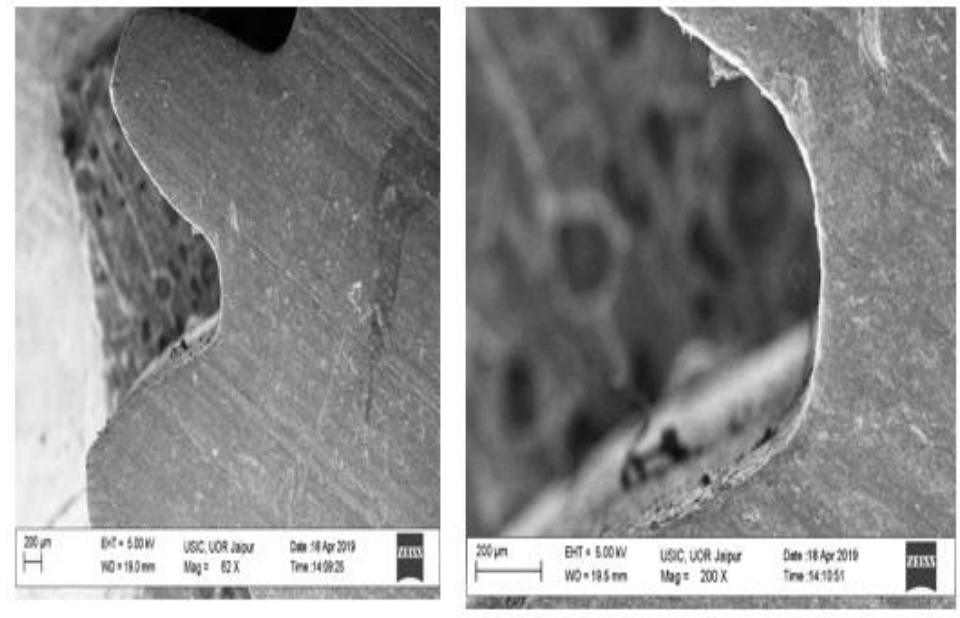

Figure 5. SEM images of gear profile.

Figure 5 presents the obtained SEM image of the machined spur gear profile. The above image shows that with the use of proper parameters the miniature gear can be free from cracks and pits. The obtained surface has uniform distribution of regular shaped crates.

\section{Conclusion}

The experiments have been performed to machine the miniature spur gears. The effects of process parameters were analysed on the material removal rate. The following conclusion has been drawn:

1. Pulse-on time and feed were found to be the most significant parameters for the optimization of the process.

2. Higher the pulse on time, larger the discharge energy was leading to increased melting and evaporation of the material and consequently higher material removal rate.

3. Lower feed rate gives maximum material removal rate as it increases spark efficiency and increases the time for material removal.

4. The optimal machining parameters can be achieved at pulse on time of $0.4 \mu \mathrm{s}$, pulse off time of 60 $\mu \mathrm{s}$ and feed rate of $6.86 \mathrm{~mm} / \mathrm{min}$ and at $7.726 \mathrm{~mm}^{3} / \mathrm{min}$ the material removal rate is obtained. 


\section{References:}

[1] Gupta, K., Laubscher, R. F., Davim, J. P., \& Jain, N. K.: Recent developments in sustainable manufacturing of gears: A review. Journal of Cleaner Production, 112 (2016), 3320-3330.

[2] Bouquet, J., Hensgen, L., Klink, A., Jacobs, T., Klocke, F., \& Lauwers, B.: Fast production of gear prototypes-a comparison of technologies. Procedia CIRP, 14, (2014), 77-82.

[3] Ali, M. Y., Karim, A. N. M., Adesta, E. Y. T., Ismail, A. F., Abdullah, A. A., \& Idris, M. N.: Comparative Study of Conventional and Micro WEDM based on Machining of Meso / Micro Sized Spur Gear, 11(5), (2010) 779-784.

[4] Gupta, K., \& Jain, N. K.: Analysis and optimization of micro-geometry of miniature spur gears manufactured by wire electric discharge machining. Precision Engineering, 38(4), (2014) 728-737.

[5] Jung, S. Y., Kang, M. C., Kim, C., Kim, C. H., Chang, Y. J., \& Han, S. M.: A study on the extrusion by a two-step process for manufacturing helical gear. The International Journal of Advanced Manufacturing Technology, 41(7-8), (2009) 684-693.

[6] Mohapatra, K. D., Dash, R., \& Sahoo, S. K.: Analysis of process parameters in wire electric discharge machining of gear cutting process using entropy grey relational analysis approach. International Journal of Manufacturing Research, 12(4), (2017) 423-443.

[7] Goyal, A.: Investigation of material removal rate and surface roughness during wire electrical discharge machining (WEDM) of Inconel 625 super alloy by cryogenic treated tool electrode. Journal of King Saud University - Science, 0-7 (2017).

[8] Benavides GL, Bieg LF, SaavedraMP, Bryce EA.: High aspect ratio meso-scale parts enabled by wire micro-EDM. Microsyst_Technol 8 (2002), 395-401.

[9] Goyal, A., Pandey, A., \& Sharma, P.: Machinability of Inconel 625 Aerospace Material Using Cryogenically Treated WEDM. In Solid State Phenomena, (2017), 266, 38-42.

[10] Mohapatraa, K., Satpathya, M., \& Sahooa, S.: Comparison of optimization techniques for MRR and surface roughness in wire EDM process for gear cutting. International Journal of Industrial Engineering Computations, (2017), 8(2), 251-262.

[11] Liao, Y. S., \& Yu, Y. P.: Study of specific discharge energy in WEDM and its application. International Journal of Machine Tools and Manufacture, (2004) 44(12-13), 1373-1380. 